\title{
LUT
}

Lappeenranta

University of Technology

Study on properties related to energy recovery from waste streams in Finland

Sermyagina Ekaterina, Nikku Markku, Vakkilainen Esa, Hyppänen Timo

This is a Author's accepted manuscript (AAM) version of a publication

published by Taylor \& Francis

in 4th Edition of the International Conference on Wastes: Solutions, Treatments and Opportunities

DOI: $10.1201 / 9781315206172-12$

Copyright of the original publication: (C) Taylor and Francis 2018

Please cite the publication as follows:

Sermyagina, E., Nikku, M., Vakkilainen, E., Hyppänen, T. (2017). Study on properties related to energy recovery from waste streams in Finland. 4th Edition of the International Conference on Wastes: Solutions, Treatments and Opportunities. DOI: 10.1201/9781315206172-12 


\title{
Study on properties related to energy recovery from waste
}

\section{streams in Finland}

\author{
E. Sermyagina, M. Nikku, E. Vakkilainen, T. Hyppänen \\ Lappeenranta University of Technology, Lappeenranta, Finland
}

ABSTRACT: Current paper presents the results of proximate analysis and heating value measurements for several different municipal solid waste (paper, cardboard, waste wood, textile, juice box carton and sewage sludge) and industrial waste fractions (bark, sawmill residue and industrial sludge). The values are compared with the fuel samples (forest residue, eucalyptus wood chips, peat and coal). Municipal solid waste fractions exhibit quite similar composition, comparable on dry basis with the industrial wood wastes, woody fuels and peat.

\section{INTRODUCTION}

\subsection{Waste management in Finland}

Reduction of waste and improvement of waste management are among the main routes in achieving resource efficient and low-waste society. The legislative framework of five-step waste hierarchy was introduced within Waste Framework Directive (EU, 2008) by the European Parliament: the waste prevention is the preferable option, followed by material re-use, recycling and other forms of recovery, with disposal (e.g. landfill) as the last choice. The main objective of the hierarchy is to extract the maximum practical benefit from the materials and to minimize amount of landfilled waste.

The waste management policies in Finland are based on the European Union waste strategy. The National Waste Plan was successfully providing the guidance for the waste management within the waste hierarchy principles until the year 2016 (the newer version of the national waste plan is currently developing). Among its objectives were to decrease of the total volume of generated municipal solid waste (MSW), to recycle $50 \%$ of municipal waste streams, generate energy from $30 \%$ and dispose less than $20 \%$ at the landfills (Ministry of the Environment, 2009). The waste disposal at landfills in Finland has significantly reduced during the recent years, as the energy recovery has increased: almost 90\% of the generated MSW was recovered in 2015.

The municipal waste consists largely of waste produced by households, though it also includes such sources as offices, public institutions and commerce. The waste streams include different organic and inorganic fractions like food waste, paper, wood, 
plastics, glass, metal and other inert materials. Generally, the waste is collected by the municipality; and the composition of the waste may vary from municipality to municipality. With regard to industrial waste, it is generally subjected to material or energy recovery on site when possible, as frequently done for example in pulp and paper industry. At the same time, certain waste fractions have to be send to the municipal waste treatment and should be subsequently treated together with the other MSW streams.

\subsection{MSW composition and analysis}

Several researchers have evaluated the chemical composition of mixed and/or separated fractions of MSW with respect to various thermochemical treatments. With regard to Northern European countries, an extensive work to assess the chemical content (heavy metals, ash content and the heating value) of the Danish MSW streams has been presented by Riber et al. (2009) and Götze et al. (2016). The notable differences in the studied properties of the residual and source-segregated waste materials were found for the parameters related to organic matter and for the elements of environmental concern. Pyrolytic degradation characteristics by thermogravimetric analysis (TGA) together with proximate and ultimate analyses were evaluated for the different waste components of MSW in Norway (Sørum et al. 2001). In an another study, the household waste in the Netherlands has been assessed with respect to elemental (heavy metals and additionally heating value) and quantitative composition (Cornelissen \& Otte, 1995).

Both quantity and chemical content of the waste materials can differ significantly with region and the season. As far as the waste treatment in Finland is concerned, the knowledge about chemical composition of MSW streams is relatively scarce. In the paper by Horttanainen et al. (2013), the qualitative composition of the mixed MSW was studied. The heating value and renewable share of energy content of the mixed waste stream was determined but the detailed evaluation of chemical composition for the separate waste streams is limited. Additionally, some data on combustible properties of the municipal solid waste in Finland is presented by Technical Research Centre of Finland (Nashrullah 2015; Ajanko et al. 2005; Alakangas, 2000). Wilén et al. (2004) discussed the possible solutions for energy generation from the waste streams in Finland with a focus on co-firing in combined heat and power plants, gasification perspectives and advanced gas cleaning.

Even though the mentioned studies cover certain amount of data on waste from different regions worldwide, this information has limited application to the specific region due to variations in the waste components and chemical composition of the waste. A com- 
prehensive characterization of MSW is scarce, possibly due to the highly heterogeneous nature of MSW and expensive procedures for this process. The objective of this paper is to improve the knowledge concerning the fuel properties of the main waste components in Finland. Plastics, paper, cardboard, textile, sewage sludge and demolition wood are the typical fractions of municipal waste in Finland. (Nasrullah 2015; Wilén et al. 2004) These waste streams were analyzed and compared along with the most common industrial wastes from a pulp and paper plant and several fuel samples (both renewable and fossil). This information is crucially important for quantifying the possibilities of energy generation from MSW.

\section{MATERIALS AND METHODS}

\subsection{Samples}

Municipal solid waste samples were collected from a landfill site in South Karelia, Finland, serving some 130.000 habitants in the region. Horttanainen et al (2013) studied the same landfill site, comparing and finding the waste composition to be similar with other Finnish landfills. Their study also indicated limited variation in the heating value of combustible waste over a longer period of time. The waste was source separated in to energy waste that could be combusted for energy production. Different fractions of common household waste, such as paper, cardboard, plastic, textile and juice box carton were sampled by hand from the waste piles. Waste (demolition) wood was also gathered from the landfill site. Sewage sludge was obtained from wastewater treatment in city of Lappeenranta after the mechanical water removal after which it is currently sent for landfilling.

Industrial waste samples were collected from a pulp and paper plant operating in the same region: samples contained bark, residue from a sawmill and industrial sludge from the plant.

Biomass fuel samples of forest residue and peat were obtained from the local power plant. Additionally, the samples of Polish (bituminous) coal and Brazilian eucalyptus (mixture of Eucalyptus Grandis and Eucalyptus Urophylla from Minas Gerais state, Brazil) were tested.

\subsection{Chemical characterization}

Standard procedures were used to characterize the waste components and fuel samples. Each sample was analyzed at least twice, and the average value was then calculated. Additionally, the samples were pelletized for determination of the heating value 
in a bomb calorimeter.

The total moisture content was determined with simplified oven dry method (CEN/TS, 2010; SFS, 2010a): samples were dried in a laboratory oven at a temperature of $105^{\circ} \mathrm{C}$ in air atmosphere until the constant mass was reached. Dried samples were then ground to under $1 \mathrm{~mm}$ particles for further analysis. The ash content of the samples was determined with the standardized procedures of EN 15403 (SFS, 2011c) and EN 14775 (SFS, 2009) by heating the sample to $550^{\circ} \mathrm{C}$ and maintaining it in a constant temperature for at least $2 \mathrm{~h}$. The procedure for determination of the volatile matter is described in the standards EN 15402 (SFS, 2011b) and EN 15148 (SFS, 2010c). The volatile mass of the sample is given by the mass loss at the temperature of $900 \pm 10^{\circ} \mathrm{C}$ in 7 min without contact with air. Fixed carbon was determined by reducing the mass of ash and volatiles from the initial mass of the dry sample. The higher heating value was determined with the Parr 6400 calorimeter, following the standard EN 15400 (SFS, 2011a) for waste components and EN 14918 (SFS, 2010b) for fuel samples.

\section{RESULTS AND DISCUSSION}

\subsection{Proximate analysis}

The results of the proximate analysis and higher heating value (HHV) measurements on dry basis are presented in Table 1 . The deviation of the resulting values between the experimental runs was below $0.3 \%$ on average for the volatile matter and the heating value and around $2.5 \%$ on average for the ash content measurements. Plastic had more than $90 \%$ of volatile matter and insignificant amount of fixed carbon $(0.2 \%)$. The ash content for all investigated MSW materials was moderate (6.6\% on average) with the only exception of paper with ash content of $36 \%$. Similar results have been published by Sørum et al. (2001) for recycled and glossy paper samples. Along with plastic, sewage sludge and juice box carton had the highest share of volatiles (82\%). The studied industrial waste materials showed comparable results: all the samples have on average $2 \%$ of ash, $78 \%$ of volatiles and $20 \%$ of fixed carbon.

Eucalyptus wood chips showed the lowest ash content among all the studied materials streams in this study, additionally they had a high volatile content. The characteristics of forest residue were naturally quite similar to the values of industrial wood waste samples due to their similar origin. Peat and coal had the highest content of fixed carbon and the lowest volatile content among all the samples, while the coal had quite high ash content (16.3\%).

It can be noted that the composition of cardboard, waste wood, textile and juice box carton are comparable to forest residue fuel and industrial wastes. At the same time, the elemental composition should be accurately assessed prior the further treatment, since these materials can contain elements that are less favorable for combustion equipment (e.g. alkalis or chlorine) or the environment (e.g. heavy metals). Especially the heavy metals are enriched in the sewage sludge. 
Table 1. The proximate analysis and higher heating value of municipal and industrial wastes and fuel samples wastes on dry basis. AC: ash content; VM: volatile matter; FC: fixed carbon; HHV: higher heating value.

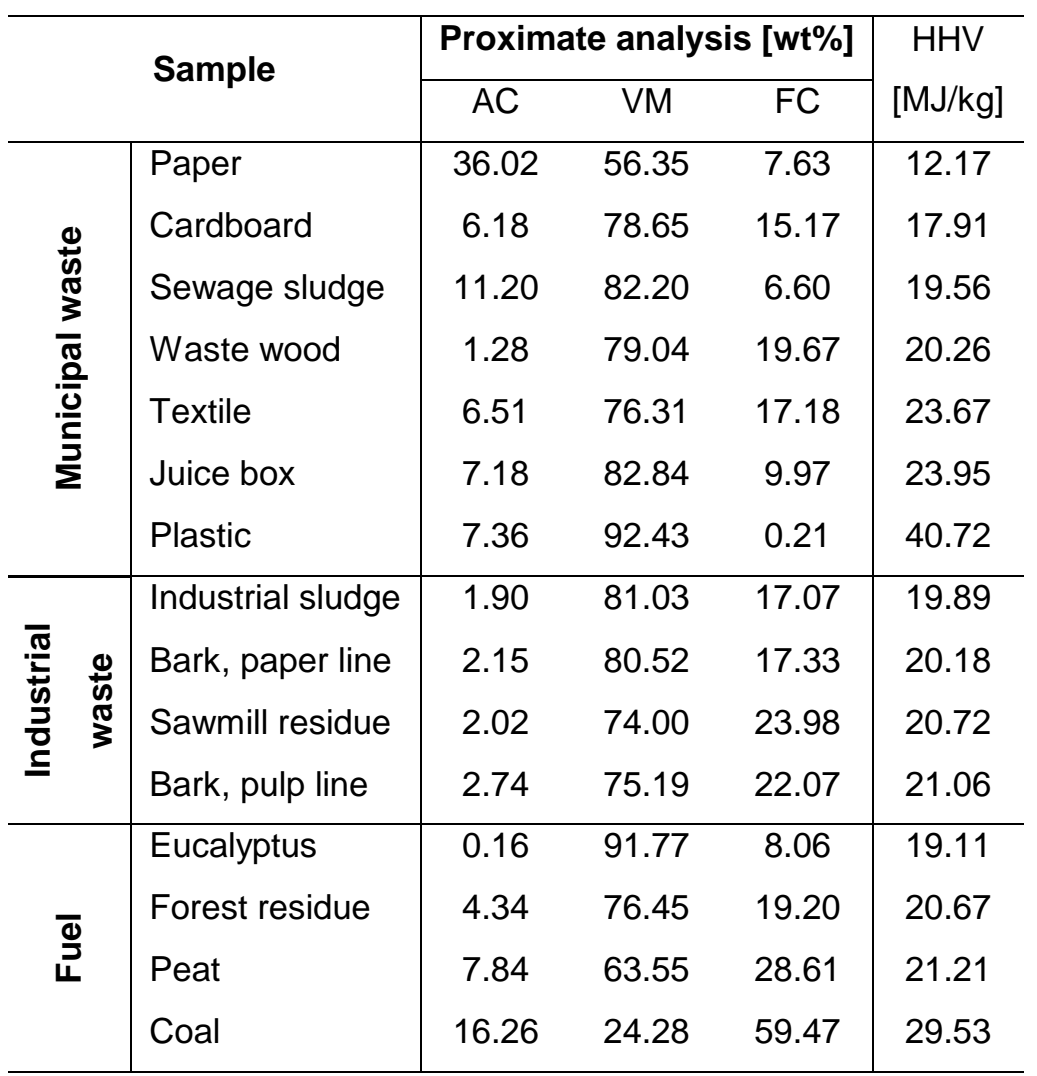

In addition, the initial moisture content of the waste streams affect significantly on their potential utilization. Figure 1 illustrates the results of the proximate analysis for the studied materials on wet basis. The data indicates that the industrial waste and biomass samples as well as sludges had the highest moisture contents, in order of $50 \%$ of the fuel mass for biomasses and over $70 \%$ for sludges. The high moisture content of sewage sludge is due to generally applied mechanical dewatering techniques: as the sludge is usually transported for landfilling, the dewatering allows to reduce the transportation and landfilling expenses. The lower moisture content could be obtained with, for example, thermal drying, but this would require additional investment on equipment and would increase the operating costs significantly. 


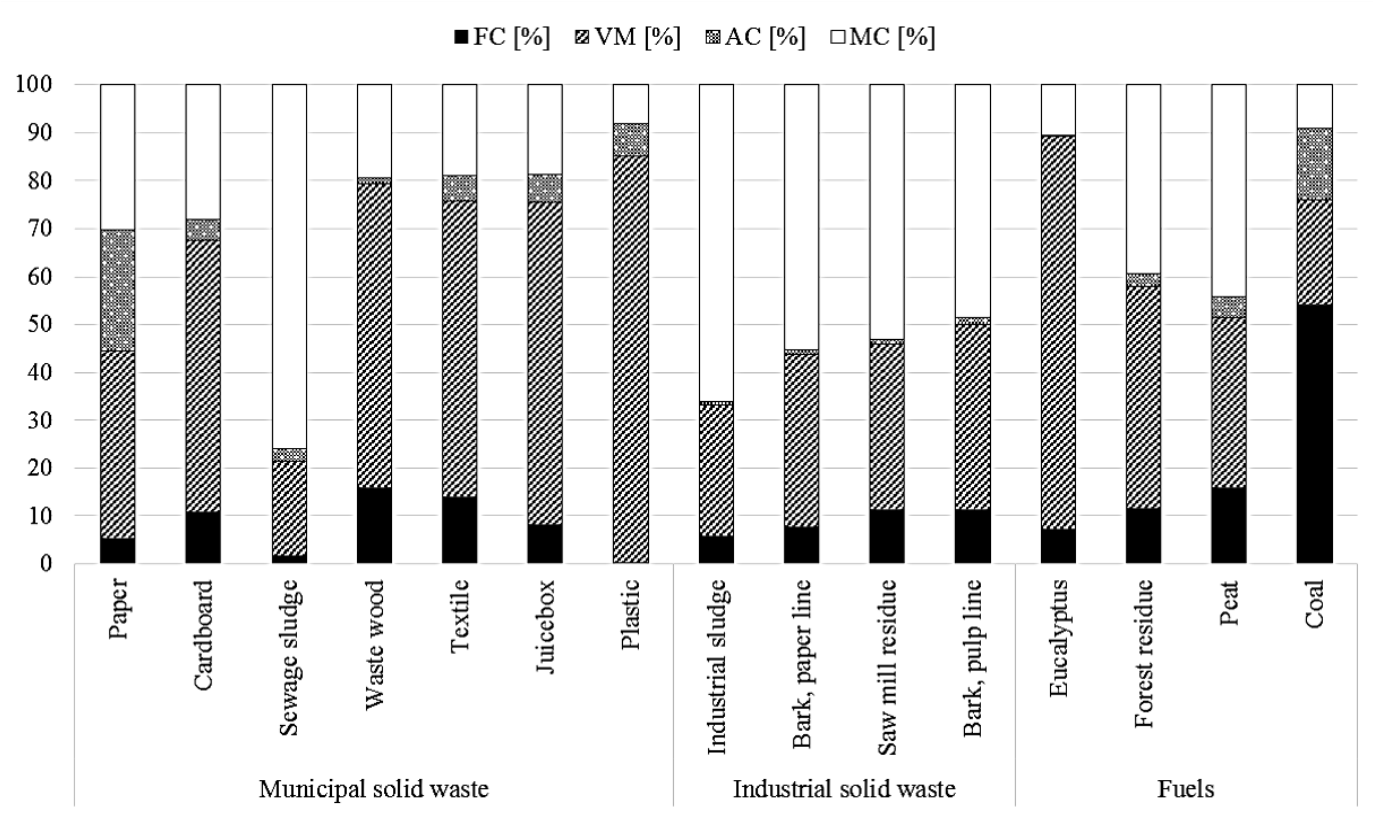

Figure 1. Proximate analysis of municipal and industrial wastes and fuel samples on wet basis.

FC: fixed carbon; VM: volatile matter; AC: ash content; MC: moisture content.

The results obtained in the current study for different fractions of municipal and industrial wastes are compared with the ones available in the literature in Figure 2. Green waste consists of grass, leaves and kitchen garbage. The comparison of the volatile matter against the fixed carbon content for each sample presents a simple classification of different waste streams. The presented data illustrates the significant heterogeneity between the typical wastes: origin, treatment and utilization methods of the initial material can affect considerably on the chemical properties of the generated waste. It can be noted that even for materials with the same origin (for instance paper materials and woody wastes) there are certain differences in the chemical composition among them due the processing. 


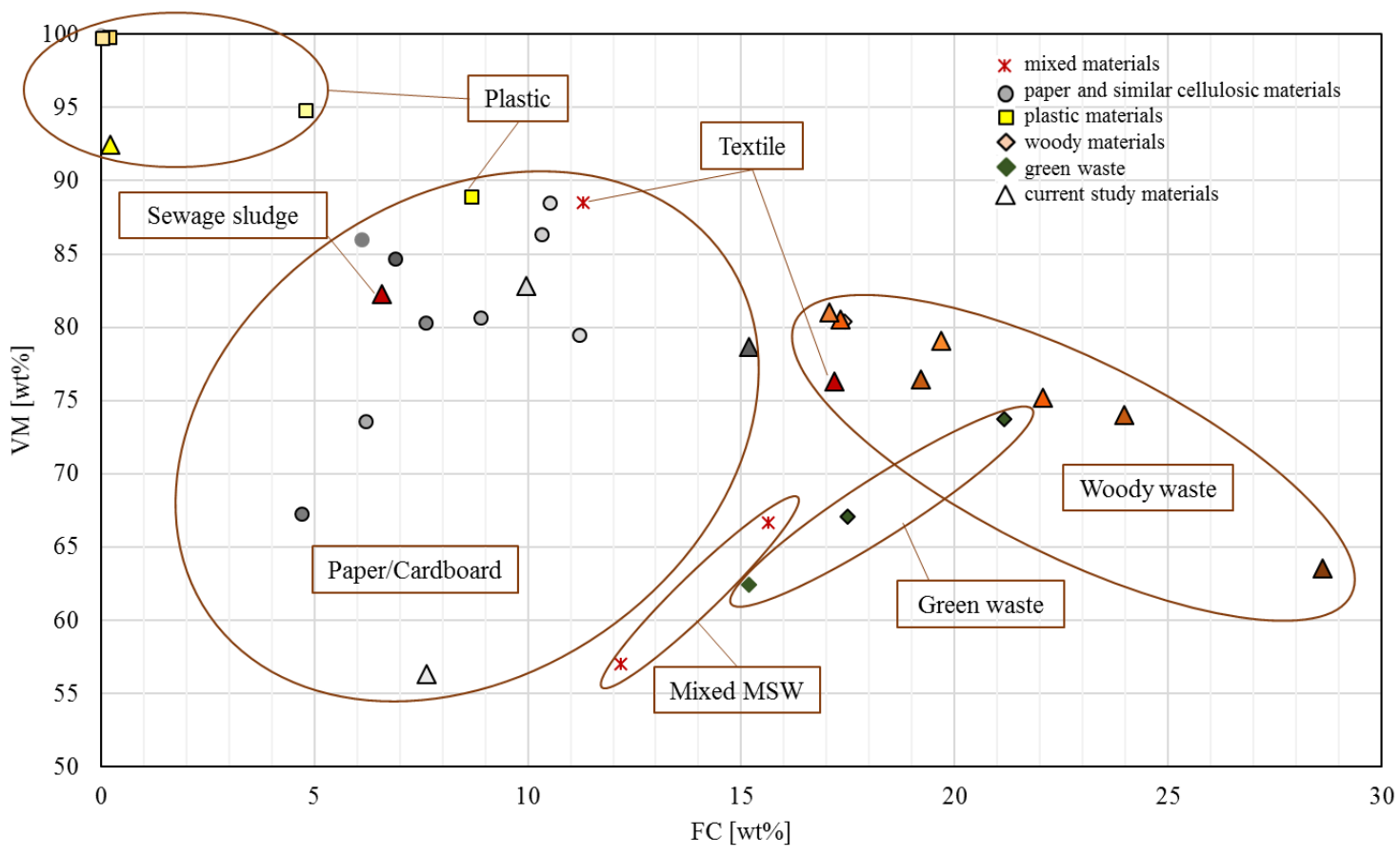

Figure 2. Volatile matter (VM) against fixed carbon (FC) of waste samples (dry basis) of the current study (triangular markers) and the available literature (Alakangas, 2000; Buah et al. 2007; Gunasee et al. 2016; Horttanainen et al. 2013; Liu et al. 2016; Sørum et al. 2001; Zhu et al. 2016).

\subsection{Heating value}

The higher heating values for all the studied samples are presented in Figure 3. It can be seen that the values for different waste fractions are of the same order as those of widely utilized fuels. The lowest heating value was found for paper, which can be explained by high share of ash (Table 1). The high heating value of plastic waste can be explained by the lower oxygen content and higher content of hydrocarbons in this oil based product compared to the cellulosic materials (Sørum et al. 2001). Since the juice box carton consists of both cellulosic fraction and some plastic with aluminum, it had higher heating value than the other studied cellulosic waste materials. It should be noted that the moisture content lowers the effective, lower heating value of the material during combustion. This results to sewage sludge with the high moisture not being as potential fuel as woody biomass. 


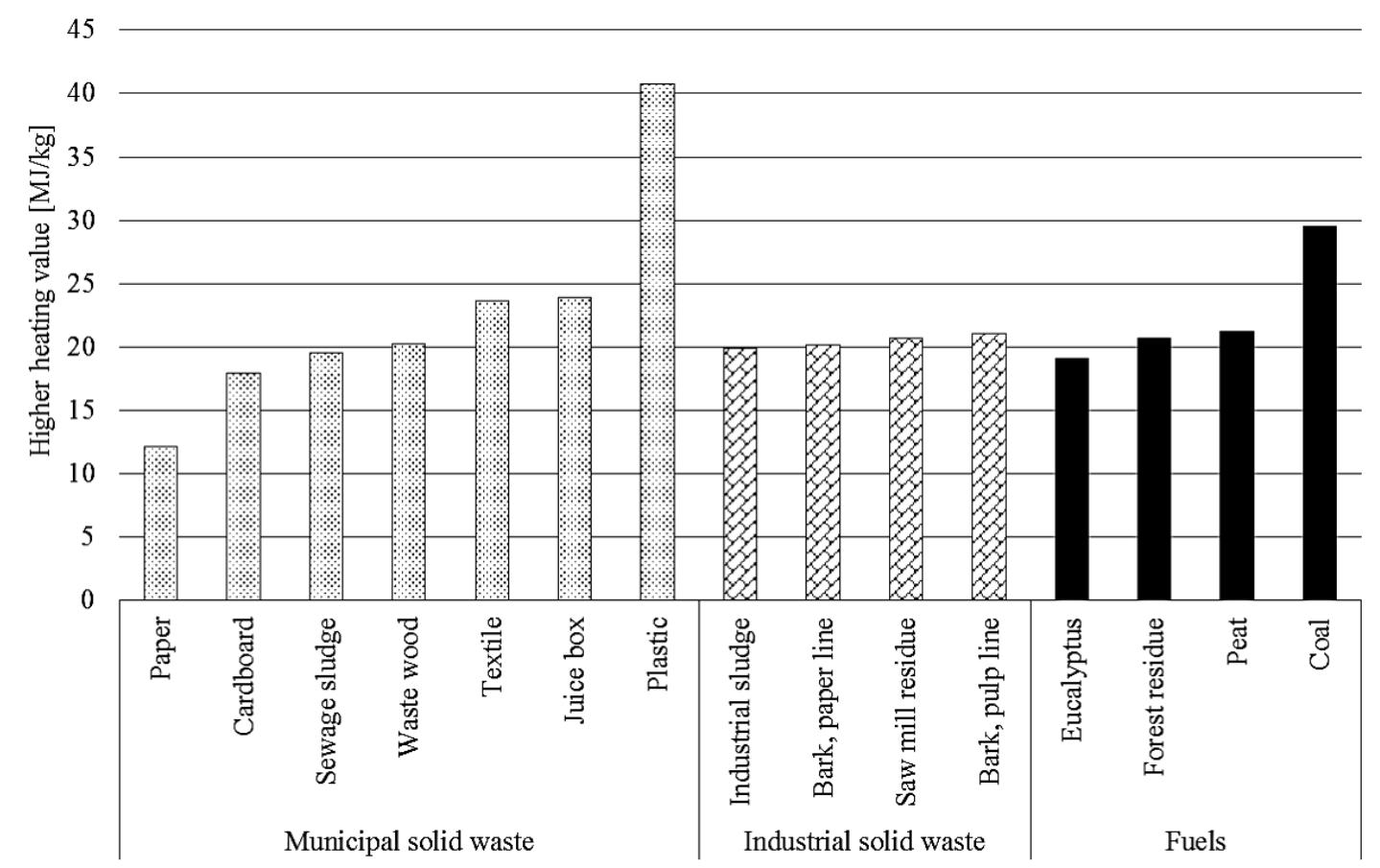

Figure 3. Higher heating values of municipal and industrial wastes and fuel samples on dry basis.

\section{CONCLUSIONS}

The fuel characteristics of common Finnish municipal solid waste fractions were determined and compared with the industrial wood wastes and four different fuels (eucalyptus chips, forest residues, peat and bituminous coal). The results of proximate analysis indicate a large heterogeneity concerning the chemical composition for the studied waste samples. Paper indicated the highest ash content (36\%) and the lowest higher heating value $(12.2 \mathrm{MJ} / \mathrm{kg})$ among all samples. Plastic had the highest volatile content $(92.4 \%)$ and the lowest fixed carbon content (0.2\%). On dry basis, MSW fractions along with sewage sludge are quite similar by characteristics with industrial wood wastes, woody fuels and peat. On the other hand, the original moisture content is relatively high for all woody materials ( $>50 \%$ for industrial wood wastes and sludges) and could lead to difficulties in energy recovery.

Besides the paper waste with the lowest heating value and the plastic waste with the highest one, all the studied waste fractions have the energy content comparable with renewable fuel samples (on dry basis). This indicates certain potential for the combined energy utilization of the considered waste streams. Nevertheless, more detailed evaluation of the elementary composition as well as the pyrolysis and combustion characteristics are required for a proper comparison of the energy recovery potential of 
waste materials. Additionally, certain hazardous elements that can be found in the waste streams (for example, in sewage sludge) should be properly identified.

\section{REFERENCES}

Ajanko, S., Moilanen, A., \& Juvonen, J. 2005. The effect of wastes' source separation system and handling technique on the quality of solid recovered fuel. Research Notes 2317. Espoo: VTT. 83 p. + app. 21 p. [In Finnish, abstract in English.]. ISBN 951-38-6753-6; 951-38-6754-4. Alakangas, E. 2000. Properties of fuels used in Finland. Research Notes 2045. Espoo: VTT. 172 p. + app. 17 p. [In Finnish, abstract in English.]. ISBN 951-38-5699-2; 951-38-5740-9.

Buah, W. K., Cunliffe, A. M., \& Williams, P. T. 2007. Characterization of Products from the Pyrolysis of Municipal Solid Waste. Process Safety and Environmental Protection, 85(5): 450-457. CEN/TS. 2010. CEN/TS 15414-2:en Solid recovered fuels. Determination of moisture content using the oven dry method. Part 2: Determination of total moisture content by a simplified method.

Cornelissen, A. A. J., \& Otte, P. F. 1995. Physical investigation of the composition of household waste in the Netherlands. National Institute of public health and environmental protection. Report 776201011.

EU. 2008. Directive 2008/98/EC of the European Parliament and of the Council of 19 November 2008 on waste and repealing certain Directives.

Gunasee, S. D., Carrier, M., Gorgens, J. F., \& Mohee, R. 2016. Pyrolysis and combustion of municipal solid wastes: Evaluation of synergistic effects using TGA-MS. Journal of Analytical and Applied Pyrolysis, 121: 50-61.

Götze, R., Pivnenko, K., Boldrin, A., Scheutz, C., \& Astrup, T. F. 2016. Physico-chemical characterisation of material fractions in residual and source-segregated household waste in Denmark. Waste Management, 54: 13-26.

Horttanainen, M., Teirasvuo, N., Kapustina, V., Hupponen, M., \& Luoranen, M. 2013. The composition, heating value and renewable share of the energy content of mixed municipal solid waste in Finland. Waste Management, 33(12): 2680-2686.

Liu, G., Liao, Y., Guo, S., Ma, X., Zeng, C., \& Wu, J. 2016. Thermal behavior and kinetics of municipal solid waste during pyrolysis and combustion process. Applied Thermal Engineering, 
98: $400-408$.

Ministry of the Environment. 2009. Towards a recycling society. The National Waste Plan for 2016. Retrieved from

https://helda.helsinki.fi/bitstream/handle/10138/38022/FE_14_2009.pdf?sequence=1

Nasrullah, M. 2015. Material and energy balance of solid recovered fuel production. Doctoral dissertation, VTT Science 115. 147 p.

Riber, C., Petersen, C., \& Christensen, T. H. 2009. Chemical composition of material fractions in Danish household waste. Waste Management, 29(4): 1251-1257.

SFS. 2009. SFS-EN 14775:en Solid biofuels. Determination of ash content.

SFS. 2010a. SFS-EN 14774-2:en Solid biofuels. Determination of moisture content using the oven dry method. Part 2: Determination of total moisture content by a simplified method.

SFS. 2010b. SFS-EN 14918:en Solid biofuels. Determination of calorific value.

SFS. 2010c. SFS-EN 15148:en Solid biofuels. Determination of the content of volatile matter. SFS. 2011a. SFS-EN 15400:en Solid recovered fuels. Determination of calorific value.

SFS. 2011b. SFS-EN 15402:en Solid recovered fuels. Determination of the content of volatile matter.

SFS. 2011c. SFS-EN 15403:en Solid recovered fuels. Determination of ash content.

Sørum, L., Gronli, M. G., \& Hustad, J. E. 2001. Pyrolysis characteristics and kinetics of municipal solid wastes. Fuel, 80(9): 1217-1227.

Wilén, C., Salokoski, P., Kurkela, E., \& Sipilä, K. 2004. Finnish expert report on best available techniques in energy production from solid recovered fuels. Helsinki, Finland. Retrieved from https://helda.helsinki.fi/bitstream/handle/10138/40639/FE_688.pdf?sequence=1 Zhu, L., Zhang, L., Fan, J., Jiang, P., \& Li, L. 2016. MSW to synthetic natural gas: System modeling and thermodynamics assessment. Waste Management, 48: 257-264. 